\title{
Pattern recognition of Hodgkin-Huxley equations by auto-regressive Laguerre Volterra network
}

\author{
Kunling Geng ${ }^{1,2^{*}}$, Vasilis Z Marmarelis ${ }^{1,2}$ \\ From 24th Annual Computational Neuroscience Meeting: CNS*2015 \\ Prague, Czech Republic. 18-23 July 2015
}

A nonparametric, data-driven nonlinear auto-regressive Volterra (NARV) [1] model has been successfully applied for capturing the dynamics in the generation of action potentials, which is classically modeled by HodgkinHuxley $(\mathrm{H}-\mathrm{H})$ equations. However, the compactness still need to be improved for further interpretations. Therefore, we propose a novel Auto-regressive Sparse Laguerre Volterra Network (ASLVN) model (shown in Figure 1A), which is developed from traditional Laguerre Volterra Network (LVN) and principal dynamic mode (PDM) framework [2].

We adopt stochastic global optimization algorithm Simulated Annealing [3] to train the ASLVN instead of Back-propagation method [2] to avoid local minima and convergence problems. We also use lasso regularization [4] to enhance the spasity of the network and prune redundant branches for parsimony. The prediction results are shown in Fig.1B, it can be seen that the exogenous output $\mathrm{z}^{(1)}$ represents the subthreshold dynamics in phase III, and the autoregressive output $z^{(2)}$ dominates in the spike shape in phase I, and the cross term output $\mathrm{z}^{(\mathrm{x})}$ helps to maintain the refractory period by cancelling the effect of $z^{(1)}$ in phase II and we also observe that refractory inhibition effect decays after initiation of AP, which explains the absolute refractory period and relative refractory period in physiology.

\begin{abstract}
Authors' details
'Biomedical Engineering Department, University of Southern California, Los Angeles, CA 90089, USA. ${ }^{2}$ Biomedical Simulations Resource, Los Angeles, CA 90089, USA.
\end{abstract}

Published: 18 December 2015

\footnotetext{
*Correspondence: kgeng@usc.edu

'Biomedical Engineering Department, University of Southern California, Los Angeles, CA 90089, USA

Full list of author information is available at the end of the article
}

References

1. Eikenberry SE, Marmarelis VZ: A nonlinear autoregressive Volterra model of the Hodgkin-Huxley equations. Journal of computational neuroscience 2013, 34(1):163-183.

2. Marmarelis VZ: Nonlinear dynamic modeling of physiological systems. John Wiley \& Sons 2004, 10.

3. Kirkpatrick S: Optimization by simmulated annealing. science 1983, 220(4598):671-680.

4. Tibshirani R: Regression shrinkage and selection via the lasso. Journal of the Royal Statistical Society Series B (Methodological) 1996, 267-288.

doi:10.1186/1471-2202-16-S1-P156

Cite this article as: Geng and Marmarelis: Pattern recognition of Hodgkin-Huxley equations by auto-regressive Laguerre Volterra network. BMC Neuroscience 2015 16(Suppl 1):P156.

Submit your next manuscript to BioMed Central and take full advantage of:

- Convenient online submission

- Thorough peer review

- No space constraints or color figure charges

- Immediate publication on acceptance

- Inclusion in PubMed, CAS, Scopus and Google Scholar

- Research which is freely available for redistribution

Submit your manuscript at www.biomedcentral.com/submit 


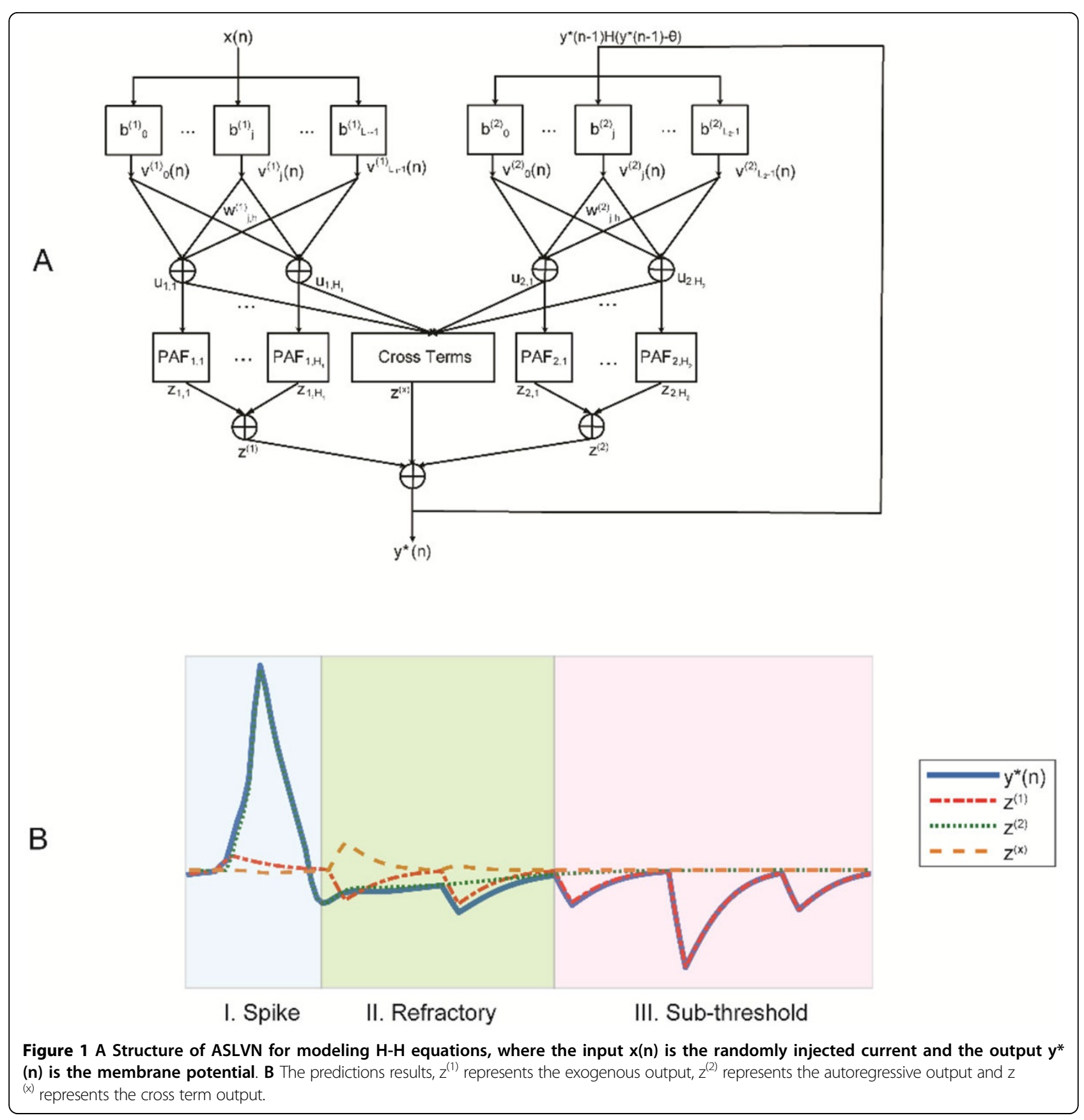

